\title{
Parâmetros zootécnicos de juvenis de pacu alimentados a diferentes frequências de arraçoamento em tanques-rede
}

\author{
Talita Gabriela Dieterich(1), Flávia Renata Potrich(1), Evandro Kleber Lorenz ${ }^{(1)}$, \\ Arcangelo Augusto Signor ${ }^{(2)}$, Aldi Feiden ${ }^{(1)}$ e Wilson Rogério Boscolo(1)
}

\begin{abstract}
(1)Universidade Estadual do Oeste do Paraná, Rua da Faculdade, №645, CEP 85903-000 Toledo, PR. E-mail: talitadiet@hotmail.com, flaviarenatapotrich@gmail.com, ekpesca@hotmail.com, aldifeiden@gmail.com, wilsonboscolo@hotmail.com ${ }^{(2)}$ Instituto Federal do Paraná, Avenida Araucária, no 780, Vila A, CEP 85860-000 Foz do Iguaçu, PR. E-mail: angelo_signor@hotmail.com
\end{abstract}

Resumo - O objetivo deste trabalho foi avaliar o desempenho zootécnico e as características bromatológicas e hematológicas de pacus alimentados a diferentes frequências de arraçoamento. Três mil e duzentos peixes, com peso inicial médio de $65,9 \pm 2,36 \mathrm{~g}$, foram distribuídos em 16 tanques-rede de $5 \mathrm{~m}^{3}$ de volume útil. Durante 65 dias, foram avaliadas quatro frequências de arraçoamento (tratamentos): T1, às 12:00 h; T2, às 8:00 e às 17:00 h; T3, às 8:00, 12:00 e 17:00 h; e T4, às 8:00, 11:00, 14:00 e 17:00 h. Utilizou-se o delineamento experimental inteiramente casualizado, com quatro repetições. Analisaram-se parâmetros de desempenho produtivo, índices de gordura visceral e hepatossomático, composição centesimal da carcaça e parâmetros hematológicos e bioquímicos. Quanto ao ganho de peso, as frequências T3 e T4 proporcionaram melhores resultados do que T1 e T2. Embora a proteína, o colesterol e os eritrócitos tenham apresentado diferenças entre os tratamentos, permaneceram dentro dos valores de referência para pacus cultivados em tanques-rede. A frequência de três arraçoamentos diários resultou em maior ganho de peso, em comparação aos demais tratamentos, sem interferir na saúde e na composição centesimal das carcaças dos animais.

Termos para indexação: Piaractus mesopotamicus, aquacultura, desempenho produtivo, hematologia, manejo alimentar.

\section{Performance parameters of juvenile pacu fed at different feeding frequencies in net cages}

\begin{abstract}
The objective of this work was to evaluate the performance parameters and the chemical composition, and the hematologic characteristics of pacu fed at different feeding frequencies. Three thousand two hundred fish, with $65.9 \pm 2.36 \mathrm{~g}$ initial weight, were distributed in 16 net cages with $5 \mathrm{~m}^{3}$ total volume. During 65 days, four feeding frequencies (treatments) were evaluated as follows: T1, at 12:00 h; T2, at 8:00 and 17:00 h; T3, at 8:00, 12:00, and 17:00 h; and T4, at 8:00, 11:00, 14:00, and 17:00 h. A completely randomized experimental design was used with four replicates. Performance parameters, visceral-somatic fat and hepatosomatic indexes, carcass proximate composition, and hematological and biochemical parameters were analyzed. For weight gain, $\mathrm{T} 3$ and $\mathrm{T} 4$ frequencies provided better results than $\mathrm{T} 1$ and $\mathrm{T} 2$. Although protein, cholesterol and erythrocytes have shown differences between treatments, they remained within the default reference range for pacus reared in net cages. The frequency of three daily feeds, resulted in better weight gain, in comparison to the other treatments, without interfering in animal health and in the proximate composition of animal carcass.
\end{abstract}

Index terms: Piaractus mesopotamicus, aquaculture, productive performance, hematology, feed handling.

\section{Introdução}

A adoção de tanques-rede para cultivo vem crescendo no Brasil (Figueiredo \& Faria, 2005). Este sistema apresenta várias vantagens em relação ao convencional, entre as quais a boa produtividade, o baixo custo, a rapidez na implantação e o rápido retorno de investimento (Ayrosa et al., 2005).

O pacu (Piaractus mesopotamicus) é uma das espécies nativas que tem potencial para aquacultura, por aceitar bem a alimentação artificial (arraçoamento), apresentar características como precocidade, rusticidade, carne de sabor agradável e bom crescimento, características que favorecem sua criação em sistemas de cultivos intensivos (Dias-Koberstein et al., 2005).

De acordo com Hayashi et al. (2004), o manejo alimentar animal é de grande relevância para o sucesso da piscicultura, por influenciar o desempenho dos indivíduos, pois está diretamente relacionada ao provimento da ração e ao consumo desta pelos peixes. 
Some-se a isto a indispensabilidade do custo com mão de obra. Tanto o manejo alimentar como a mão de obra são responsáveis por grande parcela do custo fixo da atividade e estão, assim, diretamente ligados à viabilidade econômica.

Carneiro \& Mikos (2005) afirmam que a determinação da melhor frequência de arraçoamento é de grande importância dentro do manejo aquícola, por estimular o peixe a procurar pelo alimento em momentos pré-determinados. Esse estímulo poderá contribuir para a redução da conversão alimentar, incrementar o ganho de peso, além de possibilitar maior oportunidade de observação do estado de saúde dos peixes. O conhecimento do número mais adequado de arraçoamento contribui, ainda, para reduzir o desperdício de alimento, garantir a qualidade da água e reduzir os custos de produção.

O objetivo deste trabalho foi avaliar o desempenho zootécnico e as características bromatológicas e hematológicas de pacus alimentados a diferentes frequências de arraçoamento.

\section{Material e Métodos}

O experimento foi realizado no Centro de Desenvolvimento de Tecnologias para Piscicultura em Tanques-rede, área de transição do reservatório da Itaipu Binacional, localizado no Refúgio Biológico, Município de Santa Helena, PR.

Três mil e duzentos juvenis de pacus foram

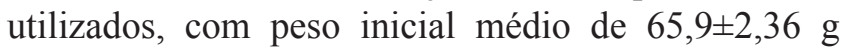
estocados em dezesseis tanques-rede dispostos em uma linha, separados pela distância de dois metros em um ambiente com profundidade média de oito metros. A estrutura dos tanques-rede era de malha de arame galvanizado recoberto de polietileno, e sustentação em alumínio com $2,0 \times 2,0 \times 1,5 \mathrm{~m}$, no total de $5 \mathrm{~m}^{3}$ de volume útil.

Os tratamentos constituíram-se da variação da frequência de arraçoamento, sendo com quatro tratamentos e quatro repetições: $\mathrm{T} 1$, uma alimentação diária às 12:00 h; T2, duas alimentações, uma às 8:00 e outra às 17:00 $\mathrm{h} ; \mathrm{T} 3$, três alimentações, uma às 8:00 $\mathrm{h}$, outra às 12:00 h, e outra às 17:00 h; e T4, quatro alimentações, uma às 8:00, e as outras às 11:00, 14:00 e 17:00 h. Os peixes receberam ração comercial extrusada com $32 \%$ de proteína bruta (Tabela 1), e o arraçoamento foi realizado até a saciedade aparente dos animais. Todos os peixes foram pesados no início (dia zero) e no $30^{\circ}$ dia. O experimento foi realizado de março a maio de 2010, no total de 65 dias de duração. No final do experimento, foi realizada a biometria (peso e comprimento total) em todos os indivíduos. Os dados obtidos foram utilizados para efetuar as análises de desempenho zootécnico de produtividade: ganho de peso (GP), sobrevivência (SO) e conversão alimentar aparente (CAA).

Os parâmetros físicos da água, temperatura e transparência foram aferidos duas vezes ao dia - às 8:00 e às 17:00 h-, com termômetro de mercúrio e disco de Secchi, respectivamente. Os parâmetros químicos - $\mathrm{pH}$, oxigênio dissolvido e condutividade elétrica foram mensurados semanalmente com potenciômetros digitais.

Os valores médios dos parâmetros de qualidade da água, durante o período experimental, foram de $24,46 \pm 2,16^{\circ} \mathrm{C}$ e $25,27 \pm 2,70^{\circ} \mathrm{C}$ quanto à temperatura, nos períodos matutino e vespertino, respectivamente,

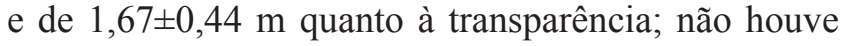
variação dos valores mensurados pela manhã e pela tarde. Quanto ao $\mathrm{pH}$, ao oxigênio dissolvido e à condutividade elétrica, os valores médios obtidos foram respectivamente de 7,63 $\pm 0,24 ; 6,66 \pm 0,13 \mathrm{mg} \mathrm{L}^{-1}$ e $80,0 \pm 9,01 \mu \mathrm{S} \mathrm{cm}^{-1}$ que, segundo Tavares (1995), são adequados para essa espécie.

No 64을 dia, os animais permaneceram em jejum por 24 horas, para o esvaziamento gástrico e, após este período, puncionaram-se $2 \mathrm{~mL}$ de sangue (seringa descartável com 10\% EDTA), em sete peixes coletados aleatoriamente de cada unidade experimental. Para este procedimento, anestesiaram-se os animais com benzocaína, à concentração de $100 \mathrm{mg} \mathrm{L}^{-1}$ (Gonçalves et al., 2008), de acordo com o protocolo no 49/09, submetido e aprovado pelo Comitê de

Tabela 1. Níveis de garantia da ração comercial (Supra Tilápia Gaiola) oferecida a $P$. mesopotamicus criados em tanques-rede $^{(1)}$.

\begin{tabular}{lc}
\hline Nutriente & Níveis de garantia \\
\hline Umidade máxima (\%) & 12 \\
Energia digestível $\left(\mathrm{kcal} \mathrm{kg}^{-1}\right)$ & 3.500 \\
Proteína bruta mínima (\%) & 32 \\
Extrato etéreo mínimo (\%) & 7 \\
Cálcio máximo (\%) & 2 \\
Fósforo mínimo $(\%)$ & 1 \\
Vitamina $\mathrm{C}\left(\mathrm{mg} \mathrm{kg}^{-1}\right)$ & 300 \\
\hline
\end{tabular}


Ética na Experimentação Animal e Aulas Práticas da Universidade Estadual do Oeste do Paraná (CEEAAP/ Unioeste). A coleta de sangue foi realizada ainda na embarcação (balsa) e transportada para a base, onde foram realizadas as análises sanguíneas.

Para cada alíquota de material, as seguintes análises foram realizadas: a contagem do número de eritrócitos, em câmara de Neubauer, sob microscópio óptico com objetiva de $40 \mathrm{X}$, após a diluição do sangue com líquido de Hayem (Collier, 1944); e a determinação de hemoglobina e hematócrito, conforme metodologia de Collier (1944) e Goldenfarb et al. (1971), respectivamente. A concentração da hemoglobina corpuscular média $(\mathrm{Chcm})$ foi calculada com os valores dos resultados obtidos, de acordo com a fórmula $\mathrm{Chcm}$ $=(\mathrm{Hb} \times 100 /$ hematócrito $)$, em que $\mathrm{Hb}=$ hemoglobina .

Nas análises bioquímicas, utilizaram-se: soro, para dosagem de proteína (Weichselbaum, 1946); triglicerídeos (Bucolo \& David, 1973; Trinder, 1969); colesterol (Trinder, 1969; Allain et al.,1974); e plasma, para a dosagem da glicose (Bergmeyer, 1986). Na obtenção do plasma, a colheita foi feita com fluoreto e o soro (sem o uso de anticoagulante). As amostras foram centrifugadas a $2.500 \mathrm{rpm}$, durante 5 min, para a determinação das análises, que foram realizadas com o uso de kits específicos Gold Analisa Diagnóstica, e a leitura foi feita em espectrofotômetro, conforme as instruções do fabricante. O método enzimático-colorimétrico foi utilizado para as dosagens de colesterol, triglicerídeos e glicose, e o colorimétrico-biureto foi utilizado para a análise de proteína.

De cada tanque-rede, dez peixes foram amostrados aleatoriamente e insensibilizados por choque térmico, em caixa com gelo, e transportados ao Laboratório de Tecnologia do Pescado da Unioeste, Campus de Toledo, para avaliação do índice de gordura víscero-somática (IGVS), do índice hepatossomático (IHS) e da composição bioquímica das carcaças. Para tanto, os animais foram pesados em balança digital e, em seguida, eviscerados. Os índices de gordura visceral e hepatossomático foram obtidos pelas eqauações descritas por Cyrino et al. (2000) como IGV $=(\mathrm{PGV} /$ PC) $\times 100$ e IHS $=($ PFíg $/$ PC $) \times 100$, em que: IGV é o índice de gordura visceral; PGV é a massa (g) da gordura visceral; PC é a massa (g) corporal; IHS é o índice hepatossomático, PFíg é a massa ( $\mathrm{g}$ ) do fígado.
As carcaças foram separadas para análise da composição química, conforme Horwitz (2005), quanto à umidade (UM), proteína bruta $(\mathrm{PB})$, extrato etéreo (EE) e matéria mineral (MM). Estas análises foram realizadas no Laboratório de Controle de Qualidade/ Gemaq da Unioeste, Campus de Toledo.

Os resultados foram submetidos à análise de variância e, quando constatadas diferenças significativas, foram submetidos ao teste de Tukey, a 5\% de probabilidade, pelo programa estatístico SAS.

\section{Resultados e Discussão}

$\mathrm{O}$ aumento da frequência alimentar proporcionou melhores resultados quanto ao ganho de peso, com a administração de três e quatro alimentações diárias (Tabela 2). Hayashi et al. (2004) encontraram resultados semelhantes ao avaliar a frequência de arraçoamento para alevinos de lambari-do-rabo-amarelo (Astyanax bimaculatus). Estes autores encontraram diferenças significativas quanto ao peso final e ao ganho de peso, em que os melhores resultados foram obtidos pelos peixes que receberam ração quatro vezes ao dia.

A frequência alimentar dos peixes é ainda influenciada pelo estágio de desenvolvimento (Deng et al., 2003), em que peixes jovens (larvas e alevinos) apresentam maior atividade metabólica e necessitam de

Tabela 2. Parâmetros de desempenho produtivo, índices de gordura visceral e hepatossomático e composição centesimal da carcaça de juvenis de pacu ( $P$. mesopotamicus), cultivados em tanques-rede e submetidos a quatro diferentes frequências de arraçoamento.

\begin{tabular}{|c|c|c|c|c|c|}
\hline \multirow[t]{2}{*}{ Parâmetro } & \multicolumn{4}{|c|}{ Frequência de arraçoamento } & \multirow{2}{*}{$\begin{array}{l}\text { CV } \\
(\%)\end{array}$} \\
\hline & 1 & 2 & 3 & 4 & \\
\hline \multicolumn{6}{|l|}{ Desempenho produtivo } \\
\hline Peso inicial (g) & 66,95 & 66,87 & 64,92 & 63,84 & 3,28 \\
\hline Ganho de peso (g) & $127,85 \mathrm{c}$ & $129,81 \mathrm{bc}$ & $141,01 \mathrm{a}$ & $139,93 \mathrm{ab}$ & 3,61 \\
\hline Sobrevivência (\%) & 99,13 & 96,33 & 98,87 & 99,33 & 8,60 \\
\hline $\mathrm{CAA}^{(2)}$ & 1,92 & 2,26 & 2,19 & 2,59 & 16,02 \\
\hline \multicolumn{6}{|l|}{ Índices } \\
\hline Gordura visceral (IGV) & 3,37 & 3,63 & 4,07 & 3,51 & 16,44 \\
\hline Hepatossomático (IHS) & 1,55 & 1,42 & 1,62 & 1,35 & 12,98 \\
\hline \multicolumn{6}{|l|}{ Composição centesimal } \\
\hline Umidade (\%) & 74,44 & 73,67 & 72,44 & 74,16 & 1,72 \\
\hline Proteína bruta $(\%)$ & 13,17 & 15,17 & 14,68 & 13,48 & 10,98 \\
\hline Lipídios (\%) & 6,68 & 6,96 & 8,26 & 6,91 & 13,53 \\
\hline Cinzas $(\%)$ & 5,54 & 5,10 & 5,55 & 5,77 & 12,94 \\
\hline
\end{tabular}

${ }^{(1)}$ Médias seguidas de letras iguais, nas linhas, não diferem entre si, pelo teste de Tukey, a $5 \%$ de probabilidade. (2) CAA, conversão alimentar aparente. 
maior frequência no fornecimento do alimento do que animais adultos (Folkvord \& Ottera, 1993). A influência da frequência alimentar sobre o desenvolvimento de juvenis foi estudada em diferentes espécies, tendo-se observado normalmente aumento do ganho de peso, quando os juvenis são alimentados mais de uma vez ao dia. Zhou et al. (2003) observaram que, em juvenis de carpa-gibel (Carassius auratus gibelio), a frequência de 24 arraçoamentos por dia apresentou os melhores resultados quanto ao desempenho de crescimento e aproveitamento do alimento. Isto mostra que, além da quantidade de alimento fornecida, a distribuição ao logo do dia (número de alimentações diárias) foi fundamental para o bom desempenho produtivo dos peixes. No presente trabalho, o arraçoamento três vezes ao dia resultou em melhor ganho de peso para o pacu (Tabela 2).

Não foram observadas variações no índice hepatossomático (IHS). O IHS é influenciado pelo ciclo reprodutivo (Barbieri et al., 1996), pelo sexo (Oliveira et al., 1997), pelas infecções e pela alimentação (Tavares-Dias et al., 2000). Por meio deste índice é possível obter informações do estado de higidez, que é influenciado pelas variações da quantidade de gordura e do glicogênio estocados no fígado.

As diferentes frequências de arraçoamento também não influenciaram a composição centesimal da carcaça do pacu (Tabela 2). Zhou et al. (2003) não observaram interferência da frequência de arraçoamento quanto aos dados de composição química de juvenis de carpa-gibel. Burkert et al. (2008) avaliaram o rendimento do processamento e da composição química de filés de surubim (Pseudoplatystoma sp.), cultivados em tanques-rede e alimentados com três rações comerciais, e também não encontraram diferença significativa na análise bromatológica entre os filés lateral e abdominal. Uma característica marcante do pacu é a deposição de lipídios (abdominal e muscular); em animais com aproximadamente $850 \mathrm{~g}$, foram encontrados $7,97 \%$ de gordura na cavidade abdominal e 3,30\% de lipídios na carcaça (Signor et al., 2010). Bittencourt et al. (2010) encontraram $7,02 \%$ de gordura visceral e $9,0 \%$ de gordura na carcaça, em pacus com $1.250 \mathrm{~g}$ cultivados em tanques-rede.

Os resultados dos eritrócitos, hematócritos e hemoglobina foram próximos aos descritos por Tavares-Dias \& Moraes (2004) como padrão para a espécie (Tabela 3). Os valores de eritrócitos foram superiores nos peixes que receberam três e quatro arraçoamentos diários. Tavares-Dias \& Mataqueiro (2004) e Tavares-Dias \& Moraes (2004) encontraram padrões de eritrócitos, em pacu em cativeiro, de 1,87 a $4,59 \times 10^{6} \mu \mathrm{L}$ a 1,63 a $3,13 \times 10^{6} \mu \mathrm{L}$, respectivamente. A função principal dos eritrócitos no sangue dos peixes é transportar oxigênio e gás carbônico (Tavares-Dias \& Moraes, 2004). Assim, os peixes que receberam maior arraçoamento diário estavam mais preparados para um possível estresse ambiental pela redução de oxigênio na água.

Os valores de hemoglobina e concentração de hemoglobina corpuscular média $(\mathrm{Chcm})$ foram maiores do que os encontrados por Lochmann et al. (2009), que avaliaram diferentes fontes de carboidratos para o pacu-vermelho (Piaractus brachypomus), e encontraram valores de 8,2 a $9,1 \mathrm{~g} \mathrm{dL}^{-1}$ e 20,8 a $23,1 \mathrm{~g} \mathrm{dL}^{-1}$, respectivamente, para hemoglobina e $\mathrm{Chcm}$.

As variáveis bioquímicas do sangue sofreram influência do arraçoamento, quanto à proteína, colesterol e triglicerídeos (Tabela 3), porém, não afetaram a glicose. Hilbig et al. (2012), ao avaliar a taxa $100,90,80$ e $70 \%$ da quantidade do arraçoamento à vontade de alimentação de pacu em tanques-rede, não observaram diferença nas variáveis bioquímicas; os valores obtidos no presente trabalho também foram semelhantes quanto aos triglicerídeos e às proteínas totais, e menores quanto à glicose e ao colesterol.

Os níveis de colesterol no sangue aprsentaram diferenças significativas entre os tratamentos. Os melhores resultados foram observados nas

Tabela 3. Parâmetros hematológicos e bioquímicos de P. mesopotamicus, cultivados em tanques-rede e submetidos a quatro diferentes frequências de arraçoamento $^{(1)}$.

\begin{tabular}{|c|c|c|c|c|c|}
\hline \multirow[t]{2}{*}{ Parâmetro } & \multicolumn{4}{|c|}{ Frequência de arraçoamento (x por dia) } & \multirow{2}{*}{$\begin{array}{l}\mathrm{CV} \\
(\%)\end{array}$} \\
\hline & 1 & 2 & 3 & 4 & \\
\hline \multicolumn{6}{|l|}{ Hematológico } \\
\hline Eritrócitos $\left(10^{6} \mu \mathrm{L}\right)$ & $1,54 \mathrm{~b}$ & $1,67 b$ & $1,92 \mathrm{a}$ & $2,05 \mathrm{a}$ & 6,17 \\
\hline Hematócritos (\%) & 34,75 & 33,12 & 36,37 & 33,87 & 6,41 \\
\hline Hemoglobina $\left(\mathrm{g} \mathrm{dL}^{-1}\right)$ & 10,86 & 11,61 & 11,92 & 11,83 & 7,65 \\
\hline Chcm $\left(\mathrm{g} \mathrm{dL}^{-1}\right)^{(2)}$ & 31,23 & 35,08 & 33,00 & 36,96 & 7,87 \\
\hline \multicolumn{6}{|l|}{ Bioquímico } \\
\hline Glicose $\left(\mathrm{mg} \mathrm{dL}^{-1}\right)$ & 55,18 & 67,08 & 50,32 & 60,48 & 22.11 \\
\hline Proteína $\left(\mathrm{g} \mathrm{dL}^{-1}\right)$ & $3,72 \mathrm{ab}$ & $4,15 \mathrm{a}$ & $3,79 \mathrm{ab}$ & $3,61 \mathrm{~b}$ & 6,06 \\
\hline Colesterol (mg dL $\left.\mathrm{m}^{-1}\right)$ & $108,81 \mathrm{a}$ & $127,20 \mathrm{ab}$ & $136,41 b$ & $140,3 b$ & 8,93 \\
\hline Triglicerídeos $\left(\mathrm{mg} \mathrm{dL}^{-1}\right)$ & 284,53 & 288,34 & 376,72 & 420,17 & 28,66 \\
\hline
\end{tabular}

${ }^{(1)}$ Médias seguidas de letras iguais, nas linhas, não diferem entre si, pelo teste de Tukey, a $5 \%$ de probabilidade. ${ }^{(2)}$ Concentração de hemoglobina corpuscular média. 
frequências de uma a duas vezes ao dia (T1 e T2) e, os piores, com frequências de três e quatro vezes ao dia para T3 e T4, respectivamente. Este efeito pode ter ocorrido em virtude do maior consumo de ração (maior ingestão de proteína e carboidrato), o que pode ter causado aumento dos níveis séricos de colesterol no sangue.

\section{Conclusão}

1. Juvenis de pacus (Piaractus mesopotamicus) cultivados em tanques-rede têm maior ganho de peso, quando alimentados três vezes ao dia.

2. A frequência de arraçoamento não influencia a composição química da carcaça e nem as variáveis hematológicas de juvenis de pacus cultivados em tanques-rede.

3. A frequência de arraçoamento influencia as variáveis bioquímicas de proteína, colesterol e triglicerídeos de juvenis de pacus cultivados em tanques-rede.

\section{Agradecimentos}

À Itaipu Binacional, pelo apoio técnico-financeiro.

\section{Referências}

ALLAIN, C.C.; POON, L.S.; CHAN, C.S.; RICHMOND, W.; FU, P.C. Enzymatic determination of total serum cholesterol. Clinical Chemistry, v.20, 470-475, 1974.

AYROSA, D.M.M. de R.; FURLANETO, F. de P.B.; AYROSA, L.M. da S. Regulamentação do acesso territorial aos tanques-rede em área de preservação permanente (APP), no Estado de São Paulo. 2005. Disponível em: $<$ http://www.pesca. sp.gov.br/textos_tecnicos.php>. Acesso em: 30 abr. 2013.

BARBIERI, G.; HARTZ, S.M.; VERANI, L.R. O fator de condição e índice hepatossomático como indicadores do período de desova de Astyanax fascialus da represa do Lobo, Estado de São Paulo (Osteichthyes, Characidae). Iheringia, v.81, p.97-100, 1996.

BERGMEYER, H.U. Methods of enzymatic analysis. $3^{\text {rd }}$ ed. Deerfield Beach: Verlag Chemie, 1986. v.6, p.178-184.

BITTENCOURT, F.; FEIDEN, A.; SIGNOR, A.A.; BOSCOLO, W.R.; LORENZ, E.K.; MALUF, M.L.F. Densidade de estocagem e parâmetros eritrocitários de pacus criados em tanques-rede. Revista Brasileira de Zootecnia, v.39, p.2323-2329, 2010. DOI: 10.1590/S1516-35982010001100002.

BUCOLO, G.; DAVID, H. Quantitative determination of serum triglycerides by the use of enzymes. Clinical Chemistry, v.19, p.476-482, 1973.

BURKERT, D.; ANDRADE, D.R. de; SIROL, R.N.; SALARO, A.L.; RASQUIDO, J.E. de A.; QUIRINO, C.R. Rendimentos do processamento e composição química de filés de surubim cultivados em tanques-rede. Revista Brasileira de Zootecnia, v.37, p.1137-1143, 2008. DOI: 10.1590/S1516-35982008000700001.

CARNEIRO, P.C.F.; MIKOS, J.D. Freqüência alimentar e crescimento de alevinos de jundiá, Rhamdia quelen. Ciência Rural, v.35, p.87-191, 2005. DOI: 10.1590/S0103-84782005000100030.

COLLIER, H.B. Standardization of blood haemoglobin determinations. Canadian Medical Association Journal, v.50, p.550-552, 1944.

CYRINO, J.E.P.; PORTZ, L.; MARTINO, R.C. Retenção de proteína e energia em juvenis de "black bass" Micropterus salmoides. Scientia Agricola, v.57, p.609-616, 2000. DOI: 10.1590/S0103-90162000000400003.

DENG, D.-F.; KOSHIO, S.; YOKOYAMA, S.; BAI, S.C.; SHAO, Q.; CUI, Y.; HUNG, S.S.O. Effects of feeding rate on growth performance of white sturgeon (Acipenser transmontanus) larvae. Aquaculture, v.217, p.589-598, 2003. DOI: 10.1016/ S0044-8486(02)00461-1.

DIAS-KOBERSTEIN, T.C.R.; CARNEIRO, D.J.; URBINATI, E.C. Tempo de trânsito gastrintestinal e esvaziamento gástrico do pacu (Piaractus mesopotamicus) em diferentes temperaturas de cultivo. Acta Scientiarum. Animal Sciences, v.27, p.413-417, 2005.

FIGUEIREDO, H.C.P.; FARIA, F.C. de. Manejo sanitário em sistemas de tanques-rede. In: CARDOSO, E.L.; FERREIRA, R.M.A.; PEREIRA, T.A.; CARDOSO, M.M.F. Cultivo de peixes em tanques-rede: desafios e oportunidades para o desenvolvimento sustentável. Belo Horizonte: Epamig, 2005. p.81-90.

FOLKVORD,A.;OTTERA,H. Effects of initial size distribution, day length, and feeding frequency on growth, survival, and cannibalism in juvenile Atlantic cod (Gadus morhua, L.). Aquaculture, v.114, p.243-260, 1993. DOI: 10.1016/0044-8486(93)90300-N.

GOLDENFARB, P.B.; BOWYER, F.P.; HALL, E.; BROSIOUS, E. Reproducibility in the hematology laboratory: the microhematocrit determination. American Journal of Clinical Pathology, v.56, p.35-39, 1971.

GONÇALVES, A.F.N.; SANTOS, E.C.C.; FERNANDES, J.B.K.; TAKAHASHI, L.S. Mentol e eugenol como substitutos da benzocaína na indução anestésica de pacu. Acta Scientiarum. Biological Sciences, v.30, p.339-344, 2008. DOI: 10.4025/ actascianimsci.v30i3.1081.

HAYASHI, C.; MEURER, F.; BOSCOLO, W.R.; LACERDA, C.H.F.; KAVATA, L.C.B. Freqüência de arraçoamento para alevinos de lambari do rabo-amarelo (Astyanax bimaculatus). Revista Brasileira de Zootecnia, v.33, p.21-26, 2004. DOI: 10.1590/S1516-35982004000100004.

HILBIG, C.C.; BOSCOLO, W.R.; FEIDEN, A.; DIETERICH, F.; LORENZ, E.K.; ZAMINHAN, M. Feeding rate for pacu reared in net cages. Revista Brasileira de Zootecnia, v.41, p.1570-1575, 2012. DOI: 10.1590/S1516-35982012000700003.

HORWITZ, W. Official Methods of Analysis of the AOAC International. $18^{\text {th }}$ ed. Gaithersburg: AOAC International, 2005.

LOCHMANN, R.; CHEN, R.G.; CHU-KOO, F.W.; CAMARGO, W.N.; KOHLER, C.C.; KASPER, C. Effects of carbohydrate-rich

Pesq. agropec. bras., Brasília, v.48, n.8, p.1043-1048, ago. 2013 DOI: 10.1590/S0100-204X2013000800033 
alternative feedstuffs on growth, survival, body composition, hematology, and nonspecific immune response of black pacu, Colossoma macropomum, and red pacu, Piaractus brachypomus. Journal of The World Aquaculture Society, v.40, p.33-44, 2009. DOI: $10.1111 /$ j.1749-7345.2008.00232.x.

OLIVEIRA, E.G. de; URBINATI, E.C.; SOUZA, V.L.; ROVIERO, D.P. Concentração de glicogênio em diferentes tecidos de pacu (Piaractus mesopotamicus), Holmberg, 1887. Boletim do Instituto de Pesca, v.24, p.89-95, 1997.

SIGNOR, A.A.; BOSCOLO, W.R.; FEIDEN, A.; BITTENCOURT, F.; COLDEBELlA, A.; REIDEL, A. Proteína e energia na alimentação de pacus criados em tanques-rede. Revista Brasileira de Zootecnia, v.39, p.2336-2341, 2010. DOI: 10.1590/ S1516-35982010001100004.

TAVARES, L.H.S. Limnologia aplicada à aqüicultura. Jaboticabal: Funep, 1995. 72p.

TAVARES-DIAS, M.; MARTINS, M.L.; MORAES, F.R. Relação hepatosomática e esplenosomática em peixes teleósteos de cultivo intensivo. Revista Brasileira de Zoologia, v.17, p.273-281, 2000. DOI: $10.1590 / \mathrm{S} 0101-81752000000100024$.
TAVARES-DIAS, M.; MATAQUEIRO, M.I. Características hematológicas, bioquímicas e biométricas de Piaractus mesopotamicus Holmberg, 1887 (Osteichthyes: Characidae) oriundos de cultivo intensivo. Acta Scientiarium. Biological Sciences, v.26, p.157-162, 2004.

TAVARES-DIAS, M.; MORAES, F.R. de. Hematologia de peixes teleósteos. Ribeirão Preto: Villimpress Complexo Gráfico, 2004. $144 \mathrm{p}$.

TRINDER, P. Determination of glucose in blood using glucose oxidase with an alternative oxygen acceptor. Annals of Clinical Biochemistry, v.6, p.24-27, 1969.

WEICHSELBAUM, T.E. An accurate and rapid method for the determination of proteins in small amounts of blood serum and plasma. American Journal of Clinical Pathology, v.10, p.40-49, 1946.

ZHOU, Z.; CUI, Y.; XIE, S.; ZHU, X.; LEI, W.; XUE, M.; YANG, Y. Effect of feeding frequency on growth, feed utilization, and size variation of juvenile gibel carp (Carassius auratus gibelio). Journal of Applied Ichthyology, v.19, p.244-249, 2003. DOI: 10.1046/j.1439-0426.2003.00453.x.

Recebido em 29 de agosto de 2011 e aprovado em 22 de julho de 2013 